\title{
Spectrum of upper gastrointestinal bleed: An experience from Eastern India
}

\author{
Md Nadeem Parvez, Mahesh Kumar Goenka, Indrajeet Kumar Tiwari, Usha Goenka ${ }^{1}$
}

Department of Gastroenterology, Institute of Gastrosciences, ${ }^{1}$ Department of Clinical Imaging and Interventional Radiology, Apollo Gleneagles Hospitals, Kolkata, West Bengal, India

\begin{abstract}
Key words Clinical presentation, etiology, outcome, upper gastrointestinal bleed
\end{abstract}

\section{Introduction}

Upper gastrointestinal bleeding (UGIB) is a gastrointestinal emergency that can result in significant morbidity, mortality, and use of health-care resources. ${ }^{[1]}$ Population-based epidemiology data are important to get insight into the actual health-care problem. The etiology of UGIB may vary in different geographical regions. Epidemiological

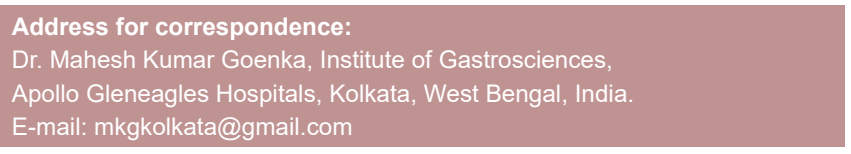

\begin{tabular}{|l|c|}
\hline \multicolumn{2}{|c|}{ Access this article online } \\
\hline \multirow{2}{*}{$\begin{array}{l}\text { Website: } \\
\text { www.jdeonline.in }\end{array}$} & Quick Response Code \\
\hline DOI: & \\
10.4103/0976-5042.189146 & \\
\hline
\end{tabular}

data are helpful in knowing the burden of the problem, the etiology, and severity of the disorder which ultimately helps in making strategies to combat morbidity and mortality. The advances in medical practice in recent decades have influenced the etiology and management of UGIB. There are only a few recent epidemiological surveys regarding acute UGIB in India. In studies done in the Western population, peptic ulcer disease still constitutes the most common cause of UGIB..$^{[1-4]}$

Few studies have shown a decrease in rates of mortality and rebleeding. ${ }^{[1,2]}$ However, other studies have failed to reproduce

This is an open access article distributed under the terms of the Creative Commons Attribution-NonCommercial-ShareAlike 3.0 License, which allows others to remix, tweak, and build upon the work non-commercially, as long as the author is credited and the new creations are licensed under the identical terms.

For reprints contact: reprints@medknow.com

How to cite this article: Parvez M, Goenka MK, Tiwari IK, Goenka U. Spectrum of upper gastrointestinal bleed: An experience from Eastern India. J Dig Endosc 2016;7:55-61. 
the same results. ${ }^{[3]}$ The mortality due to this condition has largely remained unchanged. ${ }^{[4]}$ In this study, we retrospectively analyzed the data of patients admitted with acute UGIB and noted the clinical presentation, etiology of bleed, and outcome.

\section{Materials and Methods}

We retrospectively analyzed the data of 337 consecutive patients who were admitted to Apollo Gleneagles Hospital from January 2013 to May 2015 with UGIB. The study was approved by the Institute Ethics Committee. Patients included were aged $>12$ years. A diagnosis of acute UGIB was based on the presence of hematemesis and/or melena. We retrospectively analyzed baseline clinical data, laboratory reports, transfused blood units, endoscopic records, and subsequent follow-ups until patient death or discharge.

\section{Results}

A total of 337 patients of UGIB were included in the study. Majority of $272(80.7 \%)$ patients were male and only $65(19.3 \%)$ were female (male:female ratio: $4: 1)$. The mean age of the patients was $55.11 \pm 14.8$ years (range - $14-85$ years). Majority (54\%) of the patients were in the age group of 20-60 years. Furthermore, a large proportion of patients (43\%) were in the elderly age group (age $>60$ years). Young adults (age $<20$ years) constituted a small $(2.3 \%)$ number.

The clinical presentation of the patients [Table 1] was mainly in the form of hematemesis $(n=205,60.8 \%)$. Melena as presentation was seen in $171(50 \%)$ of patients. Hypotension was noted in $50(14.8 \%)$ patients at presentation and altered sensorium in 24 (7.12\%). Table 2 shows the laboratory profile of the patients at presentation.

The most common etiology [Table 3] of UGIB was peptic ulcer, seen in $135(40.05 \%)$ patients. Varices were present in $33 \%(n=114)$ patients, whereas mucosal erosive disease was present in $17.7 \%(n=36)$ patients. Other lesions identified were Mallory-Weiss tear $(n=8)$, malignancy $(n=10)$, gastric antral vascular ectasia (GAVE) $(n=7)$, arteriovenous malformation (3), Dieulafoy lesion (7), and polyps in six patients. However, no lesion could be identified on endoscopy in $12(3.6 \%)$ patients.

Among the 135 patients presented with peptic ulcer bleed, majority had Forrest Class III ulcer ( $n=63,46.7 \%)$ followed by Forrest Ib $(n=29,21.5 \%)$, Forrest IIb $(n=15,11.1 \%)$, Forrest IIa $(n=13,9.6 \%)$, and Forrest IIc $(n=10,7.4 \%)$. Only $5(3.7 \%)$ patients had Forrest Ia ulcers with active spurting bleed. Of the 114 patients who presented with variceal bleed, $92(80.7 \%)$ had only esophageal varices (small varices in 29 [31.5\%] and large varices in $63[68.5 \%])$. While $19(16.7 \%)$ patients had both esophageal and gastric varices, isolated gastric varices were seen in $3(2.6 \%)$ patients with variceal bleed.

\begin{tabular}{lc}
\hline $\begin{array}{l}\text { Table 1: Clinical presentation of patients presenting with } \\
\text { upper gastrointestinal bleed }\end{array}$ \\
\hline Presentation & $\boldsymbol{n}(\%)$ \\
\hline Hematemesis & $205(60.8)$ \\
Melena & $171(50.7)$ \\
Hematochezia & $13(7.4)$ \\
Postural symptoms & $54(16)$ \\
Hypotension & $50(14.8)$ \\
Altered sensorium & $24(7.12)$ \\
\hline
\end{tabular}

Table 2: Laboratory parameters in patients with acute upper gastrointestinal bleed

\begin{tabular}{lc}
\hline Parameter & Mean \pm SD \\
\hline Hemoglobin $(\mathrm{g} / \mathrm{dl})$ & $8.63 \pm 3.09$ \\
Platelet count $\times 10^{3}$ cells/cumm & $160.45 \pm 117.06$ \\
Blood urea $(\mathrm{mg} / \mathrm{dl})$ & $60.90 \pm 43.18$ \\
Creatinine $(\mathrm{mg} / \mathrm{dl})$ & $0.98 \pm 0.82$ \\
SGPT $(\mathrm{IU} / \mathrm{L})$ & $50.38 \pm 70.71$ \\
SGOT $(\mathrm{IU} / \mathrm{L})$ & $59.81 \pm 71.55$ \\
ALP $(\mathrm{IU} / \mathrm{L})$ & $99.00 \pm 104.84$ \\
Bilirubin $(\mathrm{mg} / \mathrm{dl})$ & $2.25 \pm 3.48$ \\
Albumin $(\mathrm{g} / \mathrm{dl})$ & $3.532 \pm 0.59$ \\
PT (s) & $21.33 \pm 12.00$ \\
INR & $1.98 \pm 0.70$ \\
\hline SGPT=Serum glutamate-pyruvate transaminase, SGOT=Serum & \\
glutamic-oxaloacetic transaminase, ALP=Alkaline phosphatase, & \\
PT=Prothrombin time, INR=International Normalized Ratio & \\
& \\
\hline Table 3: Etiology of upper gastrointestinal bleed & \\
\hline Endoscopic diagnosis & $n(\%)$ \\
\hline Peptic ulcer disease including & $135(40.05)$ \\
duodenal and gastric ulcer & \\
Variceal bleeding & $114(33.8)$ \\
Mucosal erosive disease including & $36(10.6)$ \\
esophagitis, gastritis, and duodenitis & \\
Mallory-Weiss tear & $8(2.3)$ \\
Malignancy & $10(2.9)$ \\
Arteriovenous malformation & $3(0.8)$ \\
Gastric antral vascular ectasia & $7(2)$ \\
Dieulafoy lesion & $7(2)$ \\
Polyps & $6(1.78)$ \\
None identified & $12(3.6)$ \\
\hline & \\
\hline
\end{tabular}

\section{Etiology of bleed in different age groups}

In patients $<60$ years $(n=191)$, variceal bleed accounting for $38.2 \%(n=73)$, whereas $61.8 \%$ (118) patients had nonvariceal bleed. Furthermore, nonvariceal bleed was the more common cause of UGIB in patients aged $\geq 60$ years $(n=146)$ years accounting for $71.9 \%(n=105)$ of the cases.

\section{Comorbidities, drug intake, and addiction in patients with upper gastrointestinal bleed [Tables 4 and 5]}

One hundred and ninety-six (58.1\%) patients of the study group had comorbidities. Of them, 114 (41.8\%) patients had one long-term comorbidity, 60 (17.8\%) patients had 2 comorbidities, and $22(6.6 \%)$ patients had $\geq 3$ 
comorbidities. The most common comorbidity was chronic liver disease $118(35 \%)$. Diabetes mellitus present in $63(18.6 \%)$ patients followed by hypertension in $83(24.6 \%)$ patients. Other comorbidities were in seen in the form of Coronary artery disease (CAD) in 34 (10.8\%), chronic obstructive pulmonary disease in 30 (8.9\%), and past history of cerebrovascular accident in 11 (3.2\%) patients.

\section{Management of the patients}

Patients were managed as per standard guidelines. ${ }^{[5,6]}$ Eighty-eight (50.3\%) patients required $<2$ PRBC transfusions, whereas $60(34.3 \%)$ patients received 2-4 and $27(15.4 \%)$ patients received $>4$ transfusions. The mean duration of hospital stay was $6.6 \pm 5.79$ days. Endotherapy was required in $112(33 \%)$ in the form of combined gold probe and injection therapy in 24 (7.1) patients, Hemoclip (conventional) application in $18(5.3 \%)$ patients, OVESCO clips [Figure 2] in $6(1.7 \%)$ patients, and argon plasma coagulation [Figure 3] in $15(4.4 \%)$ patients. While band ligation was done in $40(11.8 \%)$ patients with esophageal varices, Ella stent [Figure 4] (self-expanding metal stents) was placed in $5(1.4 \%)$ patients with refractory variceal bleed. Cyanoacrylate glue injection for fundal varices was done in $8(2.3 \%)$ patients. To achieve hemostasis, ten patients also required additional hemospray powder administration.

\section{Outcome of the patients [Figure 1]}

While eleven (3.2) patients had rebleed, 9 (2.6\%) patients died during hospitalization. Surgery was required in $6(1.7 \%)$.

\begin{tabular}{lc}
\hline $\begin{array}{l}\text { Table 4: Comorbidities, drug intake, and addiction in } \\
\text { patients with upper gastrointestinal bleed }\end{array}$ \\
\hline Comorbidity & $(\%)$ \\
\hline CLD & $118(35)$ \\
COPD & $30(8.9)$ \\
CAD & $34(10.08)$ \\
CVA & $11(3.2)$ \\
CKD & $9(2.6)$ \\
Malignancy & $13(3.8)$ \\
Diabetes & $63(18.6)$ \\
HTN & $83(24.6)$ \\
NSAID & $27(8)$ \\
Antiplatelets & $30(8.9)$ \\
Vitamin K antagonist & $4(1.2)$ \\
Alcohol abuse & $63(18.7)$ \\
\hline
\end{tabular}

$\overline{\mathrm{CLD}}=$ Chronic liver disease, $\mathrm{COPD}=\mathrm{Chronic}$ obstructive pulmonary disease, $\mathrm{CAD}=$ Coronary artery disease, $\mathrm{CVA}=$ Cerebrovascular accident, $\mathrm{CKD}=$ Chronic kidney disease, HTN=Hypertension, NSAID=Nonsteroidal anti-inflammatory disease

\begin{tabular}{lc}
\hline $\begin{array}{l}\text { Table 5: Number of comorbidities in patients with upper } \\
\text { gastrointestinal bleed }\end{array}$ \\
\hline Number of comorbidities & Frequency (\%) \\
\hline 0 & $141(41.8)$ \\
1 & $114(33.8)$ \\
2 & $60(17.8)$ \\
3 & $22(6.6)$ \\
\hline
\end{tabular}

Comparison between patients with variceal and nonvariceal bleed [Tables 6 and 7]

With respect to age and gender, there was no significant difference between the patients with variceal and nonvariceal bleed. In the clinical presentation, hematemesis was significantly more seen in patients with variceal bleed, whereas melena and presence of abdominal pain were significantly more in patients with nonvariceal bleed $(P<0.05)$. While presence of chronic liver disease was as expected, significantly more in patients with variceal bleed, presence of CAD, cerebrovascular disease, and malignancies was significantly more in patients with nonvariceal bleed.

Alcohol consumption was noted significantly higher in patients with variceal bleed, whereas smoking, use of nonsteroidal anti-inflammatory drugs (NSAIDS), and antiplatelet were significantly higher in patients with nonvariceal bleed. The International normalized ratio (INR), serum bilirubin, and serum creatinine were significantly higher in patients with variceal bleed. Platelet count and serum albumin were significantly lower in patients with variceal bleed. Although the in hospital mortality was not significantly different, the rebleed rate and the need for surgery were significantly higher in patients with nonvariceal bleed.

\section{Predictors of outcome}

The following variables were analyzed in relation to outcome - age, gender, presence of hematochezia, presence of postural symptoms, hemodynamic instability on admission, presence of signs of liver cell dysfunction, laboratory parameters including blood urea, serum creatinine, platelet count, serum bilirubin, serum albumin, and INR, and blood transfusion requirements [Table 8].

\section{Predictors of mortality}

The following factors were associated with increased risk of mortality in patients undergoing UGIB - age: $\geq 65$ years, blood transfusion: $>2$ units, blood urea: $>50 \mathrm{mg} / \mathrm{dl}$, and serum albumin: $<3 \mathrm{~g} / \mathrm{dl}$. On multivariate analysis, age $\geq 65$ years (odds ratio [OR]: 9.5, 95\% confidence interval [CI]: 3.108-29.266), albumin $<3$ g/dl (OR: 3.1, 95\% CI: 1.049-9.682), and serum creatinine $>2 \mathrm{mg} / \mathrm{dl}$ (OR: 4.1, 95\% CI: 1.068-8.591) were associated with increased mortality.

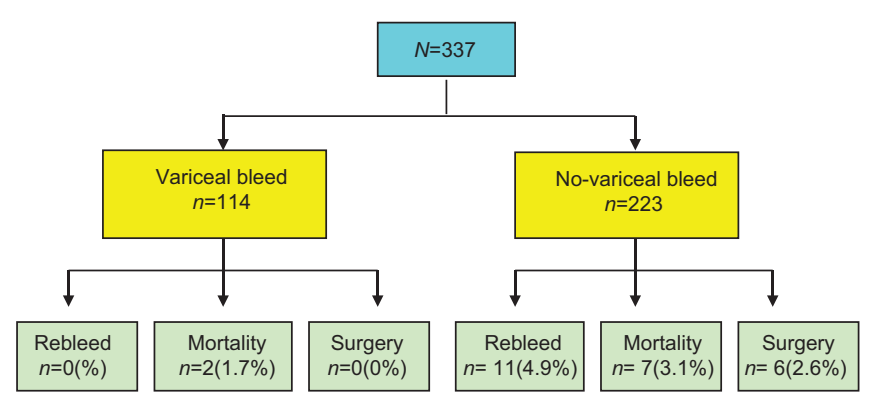

Figure 1: Outcome of the patients with acute UGI Bleed 


\begin{tabular}{lccc}
\hline \multicolumn{4}{l}{$\begin{array}{l}\text { Table 6: Differences in patients with variceal and nonvariceal } \\
\text { bleed }\end{array}$} \\
\hline Parameters & $\begin{array}{c}\text { Variceal } \\
(n=114)(\%)\end{array}$ & $\begin{array}{c}\text { Nonvariceal } \\
(n=223)(\%)\end{array}$ & $P$ \\
\hline Gender & & & \\
$\quad$ Male & $91(79.8)$ & $181(81)$ & 0.768 \\
Female & $23(20.2)$ & $42(19)$ & \\
Age & $53.16 \pm 13.7$ & $56.11 \pm 15.3$ & 0.084 \\
Hematemesis & $98(68)$ & $109(48.8)$ & 0 \\
Melena & $8(7)$ & $163(73)$ & 0 \\
Hematochezia & $1(0.8)$ & $8(3.5)$ & 0.062 \\
Pain abdomen & 0 & $27(12.1)$ & 0 \\
Smoking & $11(9.6)$ & $51(22.8)$ & 0.031 \\
NSAID use & 0 & $27(12.1)$ & 0 \\
Antiplatelet use & $4(3.5)$ & $26(11.6)$ & 0.013 \\
Anticoagulation & 0 & $4(1.7)$ & 0.150 \\
Alcohol abuse & $43(37)$ & $20(8.9)$ & 0 \\
CLD & $105(92.1)$ & $13(5.8)$ & 0 \\
CKD & $1(0.8)$ & $8(3.5)$ & 0.144 \\
CAD & $1(0.8)$ & $33(14.1)$ & 0 \\
CVA & 0 & $11(4.9)$ & 0.016 \\
GI malignancy & 0 & $13(10.3)$ & 0.009 \\
Hypotension & $15(13.1)$ & $35(15.7)$ & 0.973 \\
Postural symptoms & $14(12.2)$ & $40(17.9)$ & 0.143 \\
Rebleed rates & $1(0.8)$ & $11(4.9)$ & 0.016 \\
Need for surgery & 0 & $6(2.6)$ & 0.07 \\
Mortality index & $2(1.7) \mathrm{s}$ & $7(3.1)$ & 0.456 \\
\hline CLD Chronic & &
\end{tabular}

$\mathrm{CLD}=$ Chronic liver disease, $\mathrm{CKD}=$ Chronic kidney disease, $\mathrm{CAD}=$ Coronary artery disease, $\mathrm{CVA}=$ Cerebrovascular accident, $\mathrm{Gl}=$ Gastrointestinal, NSAID=Nonsteroidal anti-inflammatory disease

\begin{tabular}{lccc}
\hline \multicolumn{4}{l}{$\begin{array}{l}\text { Table 7: Comparison of laboratory parameters between } \\
\text { patients of variceal and nonvariceal bleed }\end{array}$} \\
\hline Parameter - mean & $\begin{array}{c}\text { Variceal } \\
\text { bleed }(\boldsymbol{n}=114)\end{array}$ & $\begin{array}{c}\text { Nonvariceal } \\
\text { bleed }(\boldsymbol{n}=223)\end{array}$ & $P$ \\
\hline Hemoglobin (g/dl) & $8.66 \pm 2.66$ & $9.46 \pm 3.23$ & 0.197 \\
Platelet count & $95 \pm 65.9$ & $201 \pm 113$ & 0.000 \\
$\times 10^{3}$ cells/cumm & & & \\
Blood urea (mg/dl) & $52.25 \pm 38.99$ & $60.20 \pm 46.9$ & 0.716 \\
Creatinine (mg/dl) & $1.00 \pm 0.79$ & $0.96 \pm 0.87$ & 0.000 \\
SGPT (IU/L) & $44.95 \pm 95.24$ & $30.85 \pm 28.60$ & 0.563 \\
SGOT (IU/L) & $72.98 \pm 62.41$ & $68.71 \pm 23.13$ & 0.651 \\
Bilirubin (mg/dl) & $3.76 \pm 4.37$ & $1.00 \pm 1.72$ & 0.000 \\
Albumin (g/dl) & $2.21 \pm 0.61$ & $3.80 \pm 0.42$ & 0.000 \\
INR & $1.74 \pm 0.70$ & $1.17 \pm 0.71$ & 0.023 \\
\hline
\end{tabular}

SGPT=Serum glutamate-pyruvate transaminase, SGOT=Serum

glutamic-oxaloacetic transaminase, INR=International Normalized Ratio

\section{Effect of comorbidity on outcome}

There was a trend, although insignificant, toward increased mortality rates with increasing comorbidities. Furthermore, there was no significant difference between rebleed and surgery in relation to a number of comorbidities.

\section{Discussion}

UGIB is one of the common medical emergencies encountered in clinical practice. The etiology of UGIB may vary in different geographical regions. Population-based

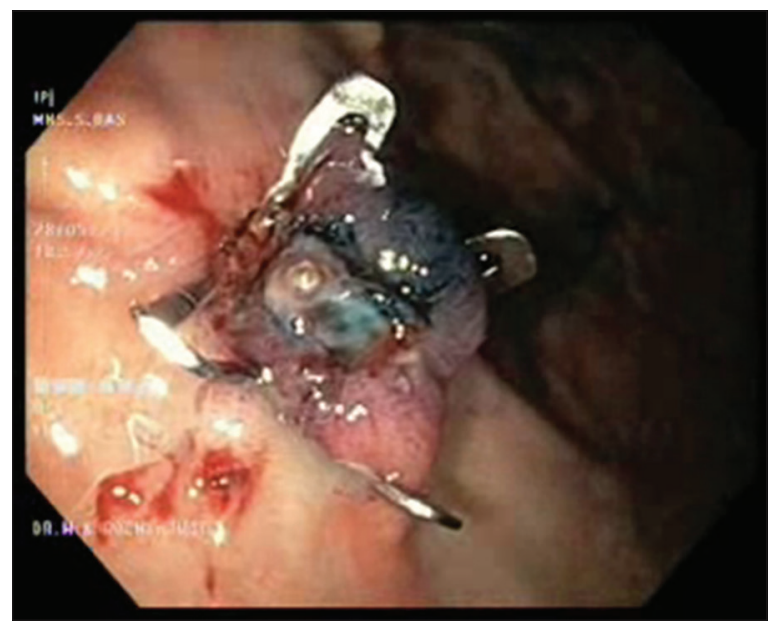

Figure 2: Actively bleeding duodenal ulcer, hemostasis achieved with OVESCO clip placement

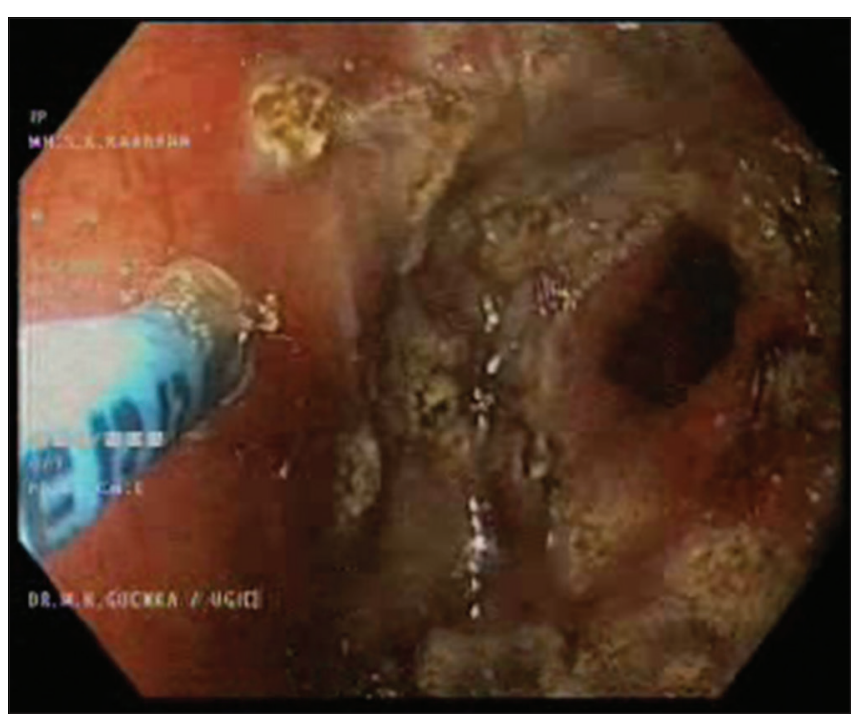

Figure 3: APC being done for bleeding gastric antral vascular ectasia

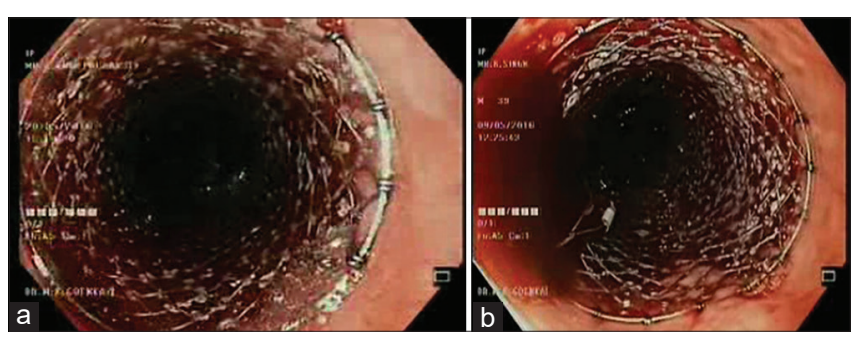

Figure 4: $(a$ and $b)$ Self-expandable esophageal covered metal stent (SX-ELLA Danis; Ella-CS, Hradec Kralove, Czech Republic) placed in a patient with refractory variceal bleed

epidemiological data revealing the current trends in India are sparse. Even fewer studies are available which simultaneously study the outcomes of both variceal and nonvariceal bleed. In this study, we retrospectively analyzed the data of 337 patients from Eastern India who presented with acute UGIB. 
Overall, the most common etiology of acute UGIB in our study was peptic ulcer disease (40\%). Variceal bleed was the second most common (33\%) etiology of UGIB in our study. This is in tune with the several previous studies [Table 9] which had shown peptic ulcer as the most common etiology of UGIB. ${ }^{[7-11]}$ In addition, in a recent study from South India, peptic ulcer was found to be the most common etiology. ${ }^{[12]}$ Another recent study from Middle East has shown that peptic ulcer disease is the most common cause of UGIB. ${ }^{[13]}$ This shows that the trend is similar with regard to the etiology of UGIB. However, this is in contrast to the reported spectra from Northern and Western India that create the impression that variceal bleeding is the most common cause of UGIB in India. ${ }^{[14-17]}$ This may

\begin{tabular}{|c|c|c|c|}
\hline \multirow[t]{2}{*}{ Variables analysed } & \multicolumn{3}{|c|}{$P$} \\
\hline & Mortality & Rebleed & Surgery \\
\hline Age $\geq 65$ years & 0 & 0.868 & 0.980 \\
\hline Gender & 0.761 & 0.623 & 0.794 \\
\hline Presence of hematochezia & 0.214 & 0.846 & 0.831 \\
\hline Presence of postural symptoms & 0.970 & 0.067 & 0.061 \\
\hline Hemodynamic instability & 0.083 & 0.351 & 0.337 \\
\hline Blood urea $\geq 50 \mathrm{mg} / \mathrm{dl}$ & 0.032 & 0.362 & 0.219 \\
\hline Serum creatinine $\geq 2 \mathrm{mg} / \mathrm{dl}$ & 0.034 & 0.184 & 0.023 \\
\hline Serum bilirubin $\geq 3 \mathrm{mg} / \mathrm{dl}$ & 0.93 & 0.026 & 0.461 \\
\hline Serum albumin $<3 \mathrm{~g} / \mathrm{dl}$ & 0.012 & 0.029 & 0.586 \\
\hline Platelet count $\leq 150 \times 10^{3}$ cells/cumm & 0.869 & 0.042 & 0.273 \\
\hline INR $\geq 2$ & 0.672 & 0.730 & 0.813 \\
\hline Hemoglobin on admission $\leq 7 \mathrm{~g} / \mathrm{dl}$ & 0.635 & 0.074 & 0.265 \\
\hline Number of comorbidities & 0.213 & 0.432 & 0.784 \\
\hline Blood transfusion $>2$ units & 0.023 & 0 & 0 \\
\hline Need for relook endoscopy & 0.564 & 0.768 & 0.089 \\
\hline
\end{tabular}

INR=International Normalized Ratio be due to the regional differences in the prevalence of chronic liver disease.

In patients $<60(n=191)$ years, variceal bleed accounted for $38.2 \%(n=73)$, whereas $61.8 \%$ (118) patients had nonvariceal bleed. In addition, nonvariceal bleed was the more common cause of UGIB in patients aged $\geq 60$ years accounting for $71.9 \%(n=105)$ of the cases. These rates were similar to those obtained in a study conducted by Charatcharoenwitthaya et al., ${ }^{[18]}$ where the acid-related disorders formed the most common endoscopic diagnosis in patients with age $\geq 65$ years with the incidence of peptic ulcer being $68 \%$. Increased incidence of antiplatelet use for comorbidities and NSAID use could explain the increased incidence of peptic ulcers in these patients. ${ }^{[18]}$

The causes of UGIB in patients with liver cirrhosis can be grouped into two categories: The first includes lesions that arise by virtue of portal hypertension, namely, gastroesophageal varices and portal hypertensive gastropathy (PHG); and the second includes lesions seen in the general population (peptic ulcer, erosive gastritis, reflux esophagitis, Mallory-Weiss syndrome, tumors, etc.). In our study, among 118 patients with CLD, variceal bleed ( $n=105$ [92\%]) was the most common cause of UGIB followed by peptic ulcer disease in 4\%, PHG and GAVE in $3 \%$, and mucosal erosive disease was seen in $1 \%$. In another study evaluating the etiology of UGIB in CLD patients done by del Olmo et al., the most common etiology was variceal bleed $53.1 \%$ followed by peptic ulcer bleed $18.7 \%$ and Mallory-Weiss tear 3.7\%. ${ }^{[19]}$

The clinical presentation of UGIB may vary. In our study, the clinical presentation of the patient was mainly in the form of

\begin{tabular}{|c|c|c|c|c|c|c|c|c|}
\hline & $\begin{array}{l}\text { Present study } \\
\text { Kolkata }\end{array}$ & Odisha $^{[9]}$ & New Delhi ${ }^{[14]}$ & Mumbai ${ }^{[15]}$ & Chennai $^{[10]}$ & Kerala $^{[11]}$ & Ahmedabad $^{[16]}$ & Shimla ${ }^{[17]}$ \\
\hline Year of study & 2016 & 2012 & 1983 & 2001 & 2007 & 2009 & 2008 & 2005 \\
\hline Study population $(n)$ & 337 & 608 & 408 & 398 & 408 & 1582 & 100 & 111 \\
\hline $\begin{array}{l}\text { PUD (duodenal ulcer } \\
+ \text { gastric) }(\%)\end{array}$ & 40.2 & 58.75 & 30 & 15.3 & 17.88 & 35. & 14 & 61.9 \\
\hline Variceal bleed (\%) & 33.8 & 12.83 & 45.5 & 56 & 33.33 & 30.97 & 37 & 10.8 \\
\hline Erosive gastritis (\%) & 10.6 & 1.18 & 8.5 & 4.5 & 43.6 & 13 & 14 & 11.7 \\
\hline Malignancy (\%) & 2.9 & 7.89 & NA & 0.75 & 2.4 & 2 & 9 & 7.2 \\
\hline
\end{tabular}

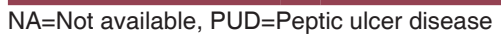

\begin{tabular}{|c|c|c|c|c|c|}
\hline Author & Study type, country & $\begin{array}{l}\text { Year, number of } \\
\text { patients }\end{array}$ & Rebleed (\%) & Mortality total (\%) & Surgery (\%) \\
\hline Current study & Retrospective, India & 2013-2015, 337 & 3.2 & 2.6 & 1.7 \\
\hline Shrestha and Sapkota ${ }^{[20]}$ & Prospective, Nepal & $2010-2013,589$ & 7.5 & 6.1 & 1.2 \\
\hline Simon et al. ${ }^{[12]}$ & Prospective & 2012,214 & 8.9 & 5.1 & 3.7 \\
\hline Ragesh et al..13] & Prospective, Qatar & 2012,251 & 8.3 & 10.3 & 4.7 \\
\hline van Leerdam ${ }^{[8]}$ & Prospective, Netherlands & 2000,769 & 16 & 13 & 7 \\
\hline Sato et al. ${ }^{[22]}$ & Retrospective, Japan & 2003-2010, 9987 & NA & 16.8 & NA \\
\hline Del Piano et al. ${ }^{[25]}$ & Retrospective, Italy & $2006-2007,1413$ & 5.4 & 4 & 14.3 \\
\hline
\end{tabular}

$\mathrm{NA}=$ Not available 
hematemesis $(60.8 \%)$. While $50 \%$ of patients presented with melena. Hematemesis was significantly higher in patients with variceal bleed, whereas melena and presence of abdominal pain were significantly more in patients with nonvariceal bleed $(P<0.05)$. As esophageal varices and gastric varices bleed more acutely and in proximity to the oral cavity, these patients tend to present more with frank hematemesis as compared to patients with PUD. Among the 135 patients presented with peptic ulcer bleed, majority of patients had clean-based ulcers (Forrest Class III ulcer $[n=63,46.7 \%]$ ) followed by Forrest Ib $(n=29,21.5 \%)$, Forrest IIb $(n=15$, $11.1 \%)$, Forrest IIa $(n=13,9.6 \%)$, and Forrest IIc $(n=10$, $7.4 \%)$. Only $5(3.7 \%)$ patients had Forrest Ia ulcers with active spurting bleed. Endoscopic therapy was given to those with active bleeding, a nonbleeding visible vessel, an adherent clot, or bleeding esophageal varices.

In our study, with respect to age and gender, there was no significant difference between the patients with variceal and nonvariceal bleed. In the clinical presentation, hematemesis was significantly more seen in patients with variceal bleed, whereas melena and presence of abdominal pain were significantly more in patients with nonvariceal bleed $(P<0.05)$. While presence of chronic liver disease was significantly more in patients with variceal bleed, presence of CAD, cerebrovascular disease, and malignancies was significantly more in patients with nonvariceal bleed. Alcohol consumption was noted significantly higher in patients with variceal bleed, whereas smoking, use of NSAIDS, and antiplatelets were significantly higher in patients with nonvariceal bleed. INR, serum bilirubin, and serum creatinine were significantly higher in patients with variceal bleed. Platelet count and serum albumin were significantly lower in patients with variceal bleed. These parameters thus actually give a clue toward the etiology of UGIB and may help in starting early appropriate therapy. Although the mortality index was not significantly different, the rebleed rate and the need for surgery were significantly higher in patients with nonvariceal bleed.

The management of patients with acute UGIB requires appropriate resuscitation, fluid and blood transfusion, and use of PPI. Vasopressin and octreotide in appropriate circumstances. Endotherapy may be required in a proportion of patients in the form of injection adrenaline, thermal coagulation, application of Hemoclips and band, and sclerosing agents in case of varices. In our study, endotherapy was required in 112 (33\%). Hence, a significant (66\%) proportion of patients did not require any form of endotherapy, rather were only managed medically. This highlights the importance of medical management in patients with UGIB.

The outcome of UGIB is varied [Table 10]. Few studies have shown a decrease in rates of mortality and rebleeding. However, other studies have failed to reproduce the same results. The mortality due to this condition has largely remained unchanged.
Traditionally quoted as between $3 \%$ and $10 \%,{ }^{[20-25]}$ more recent studies have shown improved inpatient mortality rates of $2-2.5 \% \cdot{ }^{[26,27]}$ In our study, the mortality index was $2.6 \%$ which comparatively low. This decrease in mortality may be attributed to early presentation of the patient to the hospital and appropriate management. As ours is a tertiary care, a well-equipped hospital in a metropolitan city of Eastern India, the patient generally comes from nearby areas early on. Furthermore, increased public awareness of the medical illness over the years may contribute to early presentation to the hospital.

Various factors may predict the outcome of UGIB. Of them, albumin level $<3.0 \mathrm{~g} / \mathrm{dL}$ (A), INR $>1.5$ (I), altered mental status (M), systolic blood pressure $\leq 90 \mathrm{mmHg}(\mathrm{S})$, and age $>65$ years have been shown significantly affect the outcome of acute UGIB. ${ }^{[28]}$ In our study, on multivariate analysis, age $\geq 65$ years (OR: 9.5, 95\% CI: 3.108-29.266), albumin <3 g/dl (OR: 3.1, 95\% CI: 1.049- 9.682), and serum creatinine $>2$ (OR: 4.3 , 95\% CI: $1.069-8.642$ ) were predictors of increased mortality.

\section{Conclusions}

It can be concluded from our study that peptic ulcer disease is the most common cause of UGIB whereas, and variceal bleed is the second most common cause of UGIB. In the clinical presentation, hematemesis is seen significantly more seen in patients with variceal bleed, whereas melena and presence of abdominal pain are more in patients with nonvariceal bleed. The presence of CAD, cerebrovascular disease, and malignancies is seen more commonly in patients with nonvariceal bleed. Alcohol consumption is noted to be significantly higher in patients with variceal bleed, whereas smoking, use of NSAIDS, and antiplatelets were significantly higher in patients with nonvariceal bleed. INR, serum bilirubin, and serum creatinine were significantly higher in patients with variceal bleed. Platelet count and serum albumin were significantly lower in patients with variceal bleed. Although the in hospital mortality was not significantly different, the rebleed rate and the need for surgery were significantly higher in patients with nonvariceal bleed. There was a trend toward increased mortality in patients with an increasing number of comorbidities. The mortality rate was low in our study, also the rebleed rate and need of surgery were less frequent. Elderly age, albumin $<3 \mathrm{~g} / \mathrm{dl}$, and serum creatinine $>2 \mathrm{mg} / \mathrm{dL}$ were found to be important predictors of mortality. Majority of the patients could be managed medically. Only one-third of patients required some form of endotherapy.

\section{Financial support and sponsorship}

Nil.

\section{Conflicts of interest}

There are no conflicts of interest. 


\section{References}

1. Loperfido S, Baldo V, Piovesana E, Bellina L, Rossi K, Groppo M, et al. Changing trends in acute upper-GI bleeding: A population-based study. Gastrointest Endosc 2009;70:212-24.

2. Di Fiore F, Lecleire S, Merle V, Hervé S, Duhamel C, Dupas JL, et al. Changes in characteristics and outcome of acute upper gastrointestinal haemorrhage: A comparison of epidemiology and practices between 1996 and 2000 in a multicentre French study. Eur J Gastroenterol Hepatol 2005;17:641-7.

3. Thomopoulos KC, Vagenas KA, Vagianos CE, Margaritis VG, Blikas AP, Katsakoulis EC, et al. Changes in aetiology and clinical outcome of acute upper gastrointestinal bleeding during the last 15 years. Eur J Gastroenterol Hepatol 2004;16:177-82.

4. Rockall TA, Logan RF, Devlin HB, Northfield TC. Incidence of and mortality from acute upper gastrointestinal haemorrhage in the United Kingdom. Steering Committee and members of the National Audit of Acute Upper Gastrointestinal Haemorrhage. BMJ 1995;311:222-6.

5. Laine L, Jensen DM. Management of patients with ulcer bleeding. Am J Gastroenterol 2012;107:345-60.

6. Garcia-Tsao G, Sanyal AJ, Grace ND, Carey W; Practice Guidelines Committee of the American Association for the Study of Liver Diseases; Practice Parameters Committee of the American College of Gastroenterology. Prevention and management of gastroesophageal varices and variceal hemorrhage in cirrhosis. Hepatology 2007;46:922-38.

7. Singh SP, Panigrahi MK. Spectrum of upper gastrointestinal hemorrhage in coastal Odisha. Trop Gastroenterol 2013;34:14-7.

8. van Leerdam ME. Epidemiology of acute upper gastrointestinal bleeding. Best Pract Res Clin Gastroenterol 2008;22:209-24.

9. Jutabha R, Jensen DM. Management of upper gastrointestinal bleeding in the patient with chronic liver disease. Med Clin North Am 1996;80:1035-68.

10. Krishnakumar R, Padmanabhan P, Premkumar, Selvi C, Ramkumar, Joe A. Upper GI bleed - A study of 408 cases. Indian J Gastroenterol 2007;26 Suppl 2:A133.

11. Gajendra O, Ponsek T, Varghese J, Sadasivan S, Nair P, Narayanan VA. Single center study of upper GI endoscopic findings in patients with overt and occult upper GI bleed. Indian J Gastroenterol 2009;28:A111.

12. Simon EG, Chacko A, Dutta AK, Joseph AJ, George B. Acute nonvariceal upper gastrointestinal bleeding - Experience of a tertiary care center in Southern India. Indian J Gastroenterol 2013;32:236-41.

13. Thandassery RB, Sharma M, John AK, Al-Ejji KM, Wani H, Sultan K, et al. Clinical application of AIMS65 scores to predict outcomes in patients with upper gastrointestinal hemorrhage. Clin Endosc 2015;48:380-4.

14. Anand CS, Tandon BN, Nundy S. The causes, management and outcome of upper gastrointestinal haemorrhage in an Indian hospital. Br J Surg 1983;70:209-11.

15. Rathi P, Abraham P, Jakareddy R, Pai N. Spectrum of upper gastrointestinal bleeding in Western India. Indian J Gastroenterol 2001;20 Suppl 2:A37.

16. Lakhani K, Mundhara S, Sinha R, Gamit Y, Sharma R. Clinical Profile of Acute Upper Gastro Intestinal Bleeding. Available from: http://www. japi.org/july_2008/gastro_enterology_hepatology. [Last accessed on 2012 Feb 15].

17. Kashyap R, Mahajan S, Sharma B, Jaret P, Patial RK, Rana S, et al. A clinical profile of acute upper gastrointestinal bleeding at moderate altitude. JIACM 2005;6:224-8.

18. Charatcharoenwitthaya P, Pausawasdi N, Laosanguaneak N, Bubthamala J, Tanwandee T, Leelakusolvong S. Characteristics and outcomes of acute upper gastrointestinal bleeding after therapeutic endoscopy in the elderly. World J Gastroenterol 2011;17:3724-32.

19. del Olmo JA, Peña A, Serra MA, Wassel AH, Benages A, Rodrigo JM. Predictors of morbidity and mortality after the first episode of upper gastrointestinal bleeding in liver cirrhosis. J Hepatol 2000;32:19-24.

20. Shrestha UK, Sapkota S. Etiology and adverse outcome predictors of upper gastrointestinal bleeding in 589 patients in Nepal. Dig Dis Sci 2014;59:814-22.

21. Vreeburg EM, Snel P, de Bruijne JW, Bartelsman JF, Rauws EA, Tytgat GN. Acute upper gastrointestinal bleeding in the Amsterdam area: Incidence, diagnosis, and clinical outcome. Am J Gastroenterol 1997;92:236-43.

22. Sato $M$, Tateishi $R$, Yasunaga $H$, Horiguchi $H$, Yoshida $H$, Fushimi $K$, et al. Variceal hemorrhage: Analysis of 9987 cases from a Japanese nationwide database. Hepatol Res 2015;45:288-93.

23. Button LA, Roberts SE, Evans PA, Goldacre MJ, Akbari A, Dsilva R, et al. Hospitalized incidence and case fatality for upper gastrointestinal bleeding from 1999 to 2007: A record linkage study. Aliment Pharmacol Ther 2011;33:64-76.

24. Gralnek IM, Barkun AN, Bardou M. Management of acute bleeding from a peptic ulcer. N Engl J Med 2008;359:928-37.

25. Del Piano M, Bianco MA, Cipolletta L, Zambelli A, Chilovi F, Di Matteo G, et al. The "Prometeo" study: Online collection of clinical data and outcome of Italian patients with acute nonvariceal upper gastrointestinal bleeding. J Clin Gastroenterol 2013;47:e33-7.

26. Abougergi MS, Travis AC, Saltzman JR. The in-hospital mortality rate for upper GI hemorrhage has decreased over 2 decades in the United States: A nationwide analysis. Gastrointest Endosc 2015;81:882-8.e1.

27. Laine L, Yang H, Chang SC, Datto C. Trends for incidence of hospitalization and death due to GI complications in the United States from 2001 to 2009. Am J Gastroenterol 2012;107:1190-5.

28. Saltzman JR, Tabak YP, Hyett BH, Sun X, Travis AC, Johannes RS. A simple risk score accurately predicts in-hospital mortality, length of stay, and cost in acute upper GI bleeding. Gastrointest Endosc 2011;74:1215-24 